\title{
The Incidence of Cancer and Potential Role of Sirolimus Immunosuppression Conversion on Mortality Among a Single-Center Renal Transplantation Cohort of 1,816 Patients
}

\author{
F. Branco, V. Cavadas, L. Osório, F. Carvalho, L. Martins, L. Dias, A. Castro-Henriques, and E. Lima
}

\begin{abstract}
Introduction. The chronic use of immunosuppressive drugs in renal transplant recipients increases the risk of developing de novo malignancies. Herein we analyze the incidence of de novo tumors and the potential role of sirolimus to improve cancer-specific survival among a cohort at a single center.

Methods. This retrospective analysis of our 1,816 patients allografted between January 1983 and December 2009 sought subjects who developed de novo tumors. Epidemiological and clinical data were examined using Mann-Whitney and Pearson's chi-square or Fisher exact tests for statistical comparisons of continuous and categorical variables, respectively. Kaplan-Meier survival curves were used to determine cancer-specific survival according to type of neoplasia and immunosuppressive regimen, namely, conversion to sirolimus.

Results. One hundred patients $(5.5 \%)$ were diagnosed with a de novo malignancy. The 110 different cancers were diagnosed at a median interval of 73 months after kidney transplantation. The overall cancer-specific survivals at 1 and 5 years after cancer diagnosis were $87.0 \%$ and $76.9 \%$, respectively. The 15 patients converted to sirolimus showed no difference in survival.

Conclusion. The observed frequencies of cancer in our center are consistent with the literature. Among our cohort, sirolimus did not significantly impact survival among subjects who had de novo malignancies.
\end{abstract}

$\mathbf{T}$ HE QUALITY of life and survival rates for end-stage proved after successful kidney transplantation. However, de novo malignancies after kidney transplantation have become a major concern in recent years. ${ }^{1}$ Cancer-specific mortality among renal transplant recipients is not negligible. In fact, in the next 20 years, cancer is expected to be one of the most important causes of death among this group of patients. ${ }^{2}$ Several factors have been associated with the increased incidence of de novo malignancies among transplant recipients, namely sun exposure, ${ }^{3}$ extent and duration of immunosuppression, ${ }^{4,5}$ concomitant viral infection, ${ }^{6}$ and longer pretransplantation dialysis periods. ${ }^{7}$ Among the risk factors associated with de novo malignancies in this setting, the advanced age of the transplanted population and the long-term immunosuppressive therapy are important contributors to an increased number of malignancies. ${ }^{8}$

The management of the immunosuppressive regimen in recipients who have de novo cancer after transplantation is renal disease patients who are on dialysis are im-

complex and difficult. Dose reduction or withdrawal of immunosuppression seeks to recover the recipient's defective immune system; however, it may be detrimental to graft function and survival. Ideally, the immunosuppressive regimen should not be a risk factor for cancer development. To address this concern, sirolimus, a macrocyclic lactone, has shown interesting properties. After many trials in animal models, ${ }^{9}$ conversion from cyclosporine to sirolimus in human renal transplant recipients who have cancer has resulted in complete regression of posttransplant Kaposi's sarcoma ${ }^{10}$ and lymphoproliferative diseases ${ }^{11}$ while maintaining graft

From the Urology Department (F.B., V.C., L.O., F.C., E.L.), and the Nephrology Department (L.M., L.D., A.C.-H.), Centro Hospitalar do Porto, Oporto, Portugal.

*F. Branco and V. Cavadas contributed equally to this article. Address reprint requests to Frederico Branco, Largo Prof. Abel Salazar, Hospital Geral de Santo António, 4050-001 Porto, Portugal. E-mail: fredbı@hotmail.com 0041-1345/-see front matter doi:10.1016/j.transproceed.2010.12.039 
Table 1. Epidemiological, Clinical Characteristics and Cancer-Specific Survival of Renal Transplant Patients With de Novo Malignancy According to Type of Neoplasm

\begin{tabular}{|c|c|c|c|c|c|c|c|}
\hline Characteristic & Cutaneous & Hematological & Gynecological & Gastrointestinal & Urological & Miscellaneous & Overall \\
\hline Male/female & $31 / 11$ & $9 / 2$ & $0 / 17$ & $10 / 5$ & $11 / 2$ & $3 / 4$ & $61 / 39$ \\
\hline $\begin{array}{l}\text { Age at renal } \\
\text { transplantation }(\mathrm{y})\end{array}$ & $45.5(38-54.75)$ & 37 (33.5-44) & $39(30-52)$ & $51(46-55.5)$ & $47(41-56)$ & $49(35-53)$ & $44(36.75-54)$ \\
\hline $\begin{array}{l}\text { Duration of dialysis until } \\
\text { transplantation (mo) }\end{array}$ & $44(27-72)$ & $30(16-36)$ & $45(31-66)$ & $40(25.5-55.5)$ & $30(16.5-54)$ & $36(9.5-80)$ & 41 (19-68) \\
\hline $\begin{array}{l}\text { Time interval of tumor } \\
\text { development after } \\
\text { transplantation (mo) }\end{array}$ & $73.5(28-131.75)$ & 125 (72-155.5) & $42(11-76)$ & $103(50-125.5)$ & 105 (40-137) & $43(23.5-60.5)$ & $73(28-127)$ \\
\hline $\begin{array}{l}\text { Cancer-specific survival } \\
\text { at } 1-/ 5 \text {-years after } \\
\text { cancer diagnosis (\%) }\end{array}$ & $97.8 / 95.5$ & $81.8 / 54.5$ & $94.1 / 78.4$ & $42.9 / 42.9$ & $84.6 / 67.7$ & $100 / 53.3$ & $87.0 / 76.9$ \\
\hline
\end{tabular}

function. Therefore, switching from cyclosporine to sirolimus may have a potential role to treat malignancy in transplanted patients without increasing the risk of graft rejection.

These malignancies can have three sources: transfer from the donor, recurrence of a pre-existent malignancy, and de novo. ${ }^{12-14}$ However, in this setting, the majority are de novo malignancies. ${ }^{12-14}$ Some cancers are markedly increased in solid organ transplant recipients: in particular, skin cancer, non-Hodgkin's and Hodgkin's lymphoma, Kaposi's sarcoma, anogenital cancer, renal cell carcinoma, hepatocellular carcinoma, and some sarcomas. ${ }^{15-21}$ In contrast, the incidence of the most common solid tumors in the general populationlung, prostate, colorectal, breast - is only modestly increased. ${ }^{15-21}$ Thus, it is essential not only to carefully screen the patient and donor before transplantation, but also to prevent posttransplant malignancies with general preventive measures. Therefore, excessive immunosuppression should be avoided and the best immunosuppressive regimen chosen. ${ }^{22,23}$ This article reports the incidence of de novo malignancies among renal transplant recipients in a single transplantation center and assesses the impact on survival of changing the immunosuppressive regimen by the introduction of sirolimus.

\section{METHODS}

This retrospective analysis of all 1,816 patients undergoing renal transplantation between January 1983 and December 2009 was performed using our prospective database and approved by the Institutional Review Board. We analyzed subjects developing de novo cancers under immunosuppression. We excluded patients with a pretransplantation diagnosis of cancer and those for whom donor-transmitted cancer was suspected.

The collected data included: patient age at transplantation, gender, duration of pretransplantation dialysis, donor type, immunosuppressive regimen, time to de novo tumor development, tumor type, treatment, and follow-up.

After diagnosing a de novo tumor, the usual procedure until 2003, was reduction in immunosuppression; thereafter, newly diagnosed patients were converted from a calcineurin inhibitor to a sirolimus regimen.

Follow-up visits were performed monthly. Screening for malignancy included annual abdominal ultrasound (including native kidneys and renal graft) as well as a dermatologic examination, in addition to procedures universally recommended for the general population.

The follow-up was defined as the time that had elapsed from transplantation to cancer-related death, death unrelated to cancer, or last visit with no evidence of de novo malignancy with a functioning allograft.

Continuous variables are reported as median values and interquartile range (IQR); categorical variables, as the number of occurrences $(n)$ and their frequency (\%). Mann-Whitney and Pearson's chi-square or Fisher exact tests were used for statistical comparisons of continuous and categorical variables, respectively. Kaplan-Meier survival curves were plotted to determine cancerspecific survival according to type of cancer and immunosuppressive regimen (conversion or not to sirolimus). All tests were two-sided with a significance level set at 0.05 . Statistical analysis was performed using MedCalc v.11.1.1.0 (MedCalc Software bvba, Mariakerke, Belgium).

\section{RESULTS}

Among the 1,816 renal transplant recipients, $100(5.5 \%)$ subjects were diagnosed with 110 different de novo neo-

Table 2. Epidemiological, Clinical Characteristics and Cancer-Specific Survival of Renal Transplant Patients With de Novo Malignancy According to Immunosuppression Regimen (With or Without Conversion)

\begin{tabular}{|c|c|c|c|}
\hline Characteristics & Conversion to Sirolimus & No Conversion to Sirolimus & $P$ Value \\
\hline Male/female & $8 / 7$ & $53 / 32$ & $.57^{\star}$ \\
\hline Age at renal transplantation (y) & $41(34.5-49.5)$ & $46(37-55)$ & $.26^{\dagger}$ \\
\hline Duration of dialysis until transplantation (mo) & $30(16-57)$ & $41.5(23.5-73.5)$ & $.29^{\dagger}$ \\
\hline Time interval of tumor development after transplantation (mo) & $114(50-125.5)$ & $66.5(25-128)$ & $.24^{\dagger}$ \\
\hline Cancer-specific survival at $1-/ 5$-years after cancer diagnosis (\%) & $79.4 / 79.4$ & $88.2 / 76.9$ & $.84^{\ddagger}$ \\
\hline
\end{tabular}

${ }^{*}$ Fisher's exact test.

${ }^{\dagger}$ Mann-Whitney test.

${ }^{\ddagger}$ Chi-square test. 


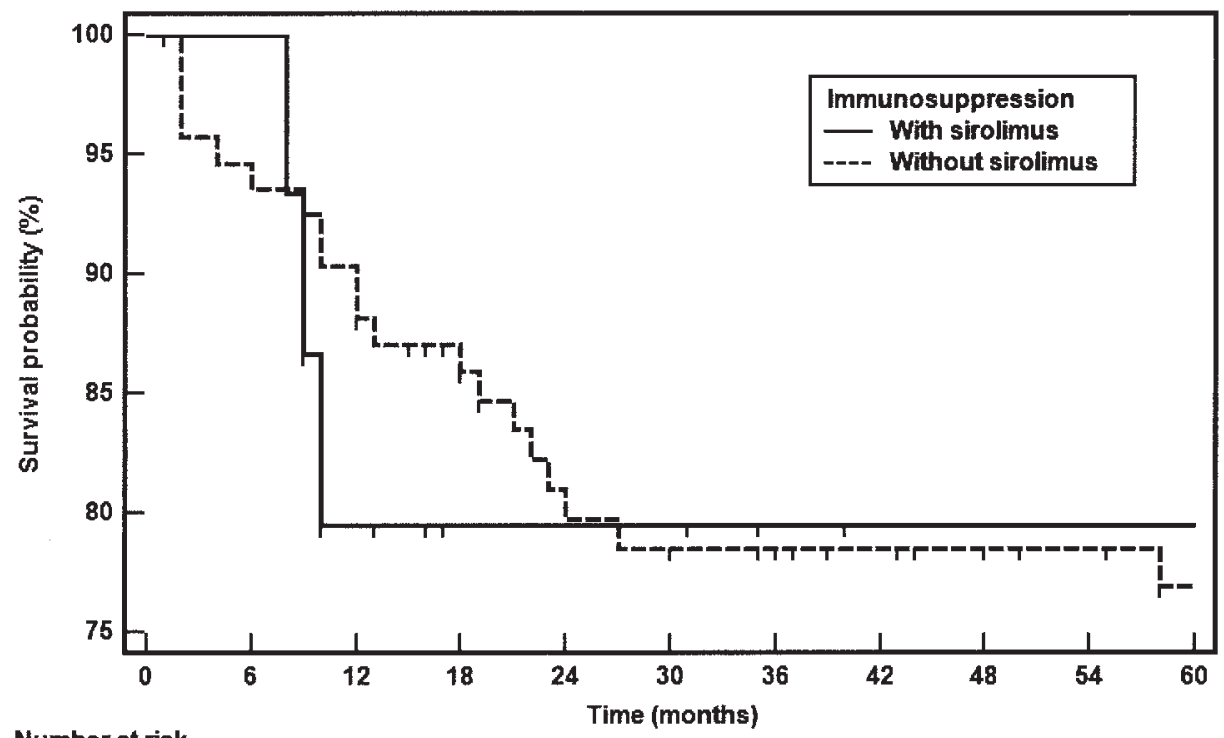

Number at risk

Group: With sirolimus

\begin{tabular}{|c|c|c|c|c|c|c|c|c|c|c|}
\hline $\begin{array}{cc}15 & 15 \\
\text { Group: } & \text { Without sirolimus }\end{array}$ & 10 & 7 & 7 & 7 & 5 & 4 & 4 & 4 & 4 & $\begin{array}{l}\text { Fig 1. Cancer-specific survival } \\
\text { curves according to immunosup- }\end{array}$ \\
\hline $\begin{array}{lll}95 & 87\end{array}$ & 80 & 72 & 64 & 61 & 59 & 57 & 53 & 52 & 49 & pression regimen. \\
\hline
\end{tabular}

plasms which were identified at a median time from transplantation of 73 months (IQR 28-127). Only two patients received a living donor organ. Table 1 shows the general features of the renal transplant recipients with de novo malignancy according to type of neoplasm. Sixty-one patients were male; the overall median age at renal transplantation was 44 years (IQR 36.75-54), the median duration of dialysis until transplantation was 41 months (IQR 19-68), and the overall cancer-specific survival at 1 and 5 years after cancer diagnosis was $87.0 \%$ and $76.9 \%$, respectively. Fortytwo patients received antithymocyte globulin induction therapy. Maintenance immunosuppression consisted of cyclosporine + prednisolone $(\mathrm{n}=57)$, cyclosporine + azathioprine + prednisolone $(\mathrm{n}=24)$, cyclosporine + mycophenolate

Fig 2. Cancer-specific survival

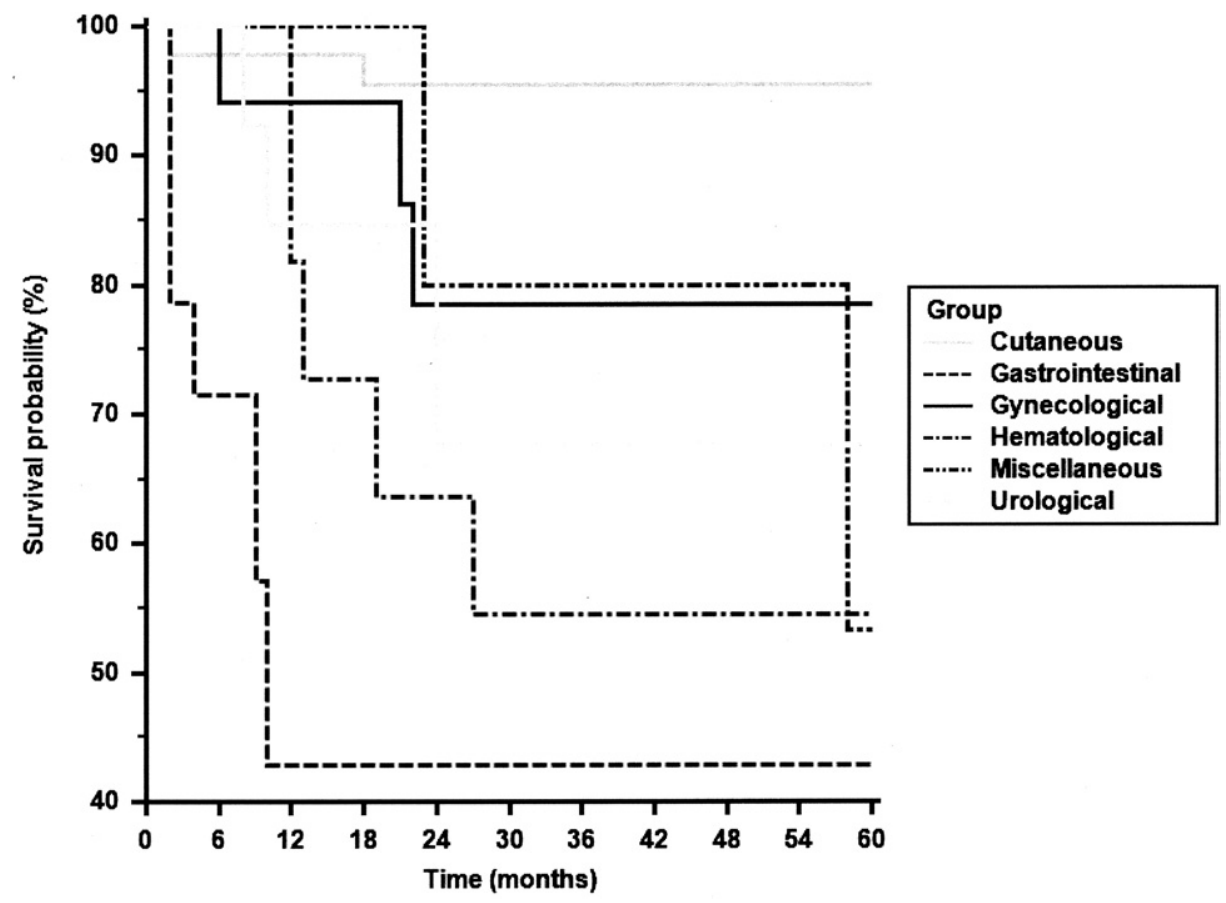
curves according to tumor type. 
mofetil + prednisolone $(\mathrm{n}=12)$, tacrolimus + mycophenolate mofetil + prednisolone $(n=6)$ and isolated tacrolimus $(\mathrm{n}=1)$.

Fifteen patients who had de novo malignancies were converted to sirolimus. No statistically relevant differences were observed concerning clinical characteristics or tumorspecific survival between patients converted or not to sirolimus (Table 2). Table 3 depicts the distribution of cancer types and mortality according to immunosuppression regimen. The cancer-specific survival curves according to immunosuppressive regimen and tumor type are shown in Figures 1 and 2.

\section{DISCUSSION}

In our cohort, the global incidence of 5.5\% (100 patients who developed 110 de novo malignancies) is consistent with the literature. ${ }^{18}$ The relative frequency of de novo malignancies was also similar to previous studies, with a significant predominance of cutaneous (melanoma and nonmelanoma) neoplasms; whereas other malignancies, such as colorectal, prostate, and stomach cancer, showed only slight increases. $^{18,24-26}$

Regarding cancer-specific survival, no significant differences were noted between sirolimus conversion or no- sirolimus regimens. Because sirolimus was only recently introduced in our clinical practice, our cohort exhibits a shorter follow-up for the this regimen. Also, the number of patients who have de novo malignancies under immunosuppressive regimens with sirolimus was smaller (although every recent patient with de novo malignancy has been converted to a sirolimus immunosuppressive regimen) which limits the comparisons and may justify the lack of a significant difference in survival. Comparing the two groups according to immunosuppressive regimen, potentially more aggressive tumors in the sirolimus group could account for the lack of survival benefit. Gastrointestinal tumors have a dismal prognosis, whereas cutaneous neoplasms show the best survival. Finally, the pattern of initial immunosuppression and its heterogeneity in patients who develop de novo cancers may have important roles influencing the survival of these patients.

Sirolimus displays a different immunosuppressive mechanism from cyclosporine. It complexes with FK binding protein complex 12 , thereafter binding with high affinity to the mammalian target of rapamycin. Conversion from cyclosporine to sirolimus in renal allograft patients who have de novo Kaposi's sarcoma ${ }^{10}$ or de novo lymphoproliferative disease ${ }^{11}$ was associated with regression of the

Table 3. Distribution of Cancer Types and Number of Deaths According to Immunosuppression Regimen (With or Without Conversion to Sirolimus)

\begin{tabular}{|c|c|c|c|c|c|c|c|}
\hline \multirow[b]{2}{*}{ Type of Cancer } & \multirow[b]{2}{*}{$\mathrm{N}$} & \multirow[b]{2}{*}{$\%$} & \multicolumn{2}{|c|}{ Conversion to Sirolimus } & \multicolumn{2}{|c|}{ No Conversion to Sirolimus } & \multirow[b]{2}{*}{$P$ Value* } \\
\hline & & & Total & Deceased & Total & Deceased & \\
\hline Skin BCC & 18 & 16.4 & - & - & 18 & - & 1 \\
\hline Skin SCC & 18 & 16.4 & 1 & - & 17 & 1 & \\
\hline Melanoma & 1 & 0.9 & - & - & 1 & 1 & \\
\hline Kaposi sarcoma & 6 & 5.5 & 2 & - & 4 & - & \\
\hline Other skin cancer & 3 & 2.7 & - & - & 3 & - & \\
\hline $\mathrm{NHL}$ & 9 & 8.2 & 2 & - & 7 & 4 & 0.45 \\
\hline Hodgkin lymphoma & 2 & 1.8 & - & - & 2 & 1 & \\
\hline Breast & 7 & 6.4 & 1 & - & 6 & 2 & 1 \\
\hline Ovary & 2 & 1.8 & - & - & 2 & 1 & \\
\hline Cervix & 3 & 2.7 & 1 & - & 2 & - & \\
\hline Vulva & 6 & 5.5 & - & - & 6 & - & \\
\hline Stomach & 6 & 5.5 & 2 & 1 & 4 & 2 & 1 \\
\hline Duodenum & 1 & 0.9 & - & - & 1 & - & \\
\hline Colon & 5 & 4.5 & 2 & 1 & 3 & 1 & \\
\hline Liver & 3 & 2.7 & - & - & 3 & 3 & \\
\hline Kidney & 6 & 5.5 & 2 & - & 4 & - & 1 \\
\hline Urothelium & 3 & 2.7 & 1 & 1 & 2 & 1 & \\
\hline Prostate & 4 & 3.6 & - & - & 4 & 1 & \\
\hline Lung & 1 & 0.9 & - & - & 1 & 1 & 1 \\
\hline Soft tissue sarcoma & 1 & 0.9 & - & - & 1 & 1 & \\
\hline Mouth & 1 & 0.9 & - & - & 1 & - & \\
\hline Parotid gland & 1 & 0.9 & - & - & 1 & - & \\
\hline \multirow[t]{2}{*}{ Thyroid } & 3 & 2.7 & 1 & - & 2 & - & \\
\hline & 110 & 100 & 15 & 3 & 95 & 20 & 1 \\
\hline
\end{tabular}

BCC, basal cell carcinoma; SCC, squamous cell carcinoma; NHL, Non-Hodgkins lymphoma.

${ }^{\star}$ Fisher's exact test. 
malignancy with a survival benefit. In a single-center study of 1,008 renal transplants followed up for 5 years, a combination regimen of sirolimus plus corticosteroid resulted in a reduction in the incidence of non-melanoma skin cancers as well as of native renal cell carcinoma. ${ }^{27}$ However, sirolimus has its own set of side effects, such as dyslipidemia, bone narrow suppression, reduced or delayed wound healing, decreased insulin sensivity, and impaired male fertility $^{28}$; additionally, grafts can leak more proteins when treated with sirolimus. ${ }^{29}$ Furthermore, the use of a de novo sirolimus-based, calcineurin inhibitor-free regimen has a distinct learning curve, requiring appreciation of these side effects, patient education, and careful monitoring of blood levels. In a large, primarily European, multicenter trial, a low-dose sirolimus regimen yielded worse outcomes owing to an excess acute rejection rate. ${ }^{30}$

Thus, it is important to have data that properly assess the safety and advantage of preventing and even treating de novo malignancies after transplantation with sirolimus, to balance the difficult side effect profile.

We acknowledge some limitations in our study: the small number of patients, its retrospective nature, varying follow-up intervals, heterogeneity of neoplasms, and tumor behavior, as well as variable immunosuppression limits our ability to draw conclusions. Nevertheless, our study provides additional data in a large cohort of transplant patients. Previous reports suffer from the same limitations. Therefore, it is important to have powerful data with larger series (which are still lacking in the literature). It is of paramount importance to conduct randomized clinical trials to elucidate the best immunosuppressive regimen with the lowest risk of developing de novo cancer, and with fewer side effects.

It is strictly important to have evidence-based data to know if differences among immunosuppressive drugs in carcinogenic activity are clinically relevant in terms of survival; if the immunosuppressive therapy should be adapted to pretransplant malignancy risk; and, lastly, what is the best approach to manage the immunosuppressive regimen after a renal recipient develops a de novo malignancy.

\section{REFERENCES}

1. Adams PI: Long-term patient survival: strategies to improve overall health. Am J Kidney Dis 47:65, 2006

2. Buell JF, Gross TG, Woodle ES: Malignancy after transplantation. Transplantation 80:254, 2005

3. Ramsay HM, Fryer AA, Hawley CM, et al: Factors associated with nonmelanoma skin cancer following renal transplantation in Queensland, Australia. J Am Acad Dermatol 49:397, 2003

4. Bordea C, Wojnarowska F, Millard PR, et al: Skin cancers in renal-transplant recipients occur more frequently than previously recognized in a temperate climate. Transplantation 77:574, 2004

5. Ducloux D, Carron P-L, Rebibou J-M, et al: CD4 lymphocytopenia as a risk factor for skin cancers in renal transplant recipients. Transplantation 65:1270, 1998

6. Miller G, Rigsby MO, Heston L, et al: Antibodies to butyrateinducible antigens of Kaposi's sarcoma-associated herpesvirus in patients with HIV-1 infection. N Engl J Med 334:1292, 1996
7. Kauffman HM, McBride MA, Delmonico FL: First report of the United Network for Organ Sharing Transplant Tumor Registry: Donors with a history of cancer. Transplantation 70:1747, 2000

8. Kauffman HM, Cherikh WS, McBride MA, et al: Posttransplant de novo malignancies in renal transplant recipients: the past and present. Transpl Int 19:607, 2006

9. Eng CP, Sehgal SN, Vézina C: Activity of rapamycin (AY22,989) against transplanted tumors. J Antibiot (Tokyo) 37:1231, 1984

10. Campistol JM, Gutierrez-Dalmau A, Torregrosa JV: Conversion to sirolimus: a successful treatment for posttransplantation Kaposi's sarcoma. Transplantation 77:760, 2004

11. Garcia VD, Bonamigo Filho JL, Neumann J, et al: Rituximab in association with rapamycin for post-transplant lymphoproliferative disease treatment. Transpl Int 16:202, 2003

12. Kauffman HM: Malignancies in organ transplant recipients. J Surg Oncol 94:431, 2006

13. Sheil AG: Donor-derived malignancy in organ transplant recipients. Transplant Proc 33:1827, 2001

14. Penn I: Donor transmitted disease: cancer. Transplant Proc 23:2629, 1991

15. Saeian K, Franco J, Komorowski RA, et al: Hepatocellular carcinoma after renal transplantation in the absence of cirrhosis or viral hepatitis: a case series. Liver Transpl Surg 5:46, 1999

16. Penn I: Malignant melanoma in organ allograft recipients. Transplantation 61:274, 1996

17. Birkeland SA, Lokkegaard H, Storm HH: Cancer risk in patients on dialysis and after renal transplantation [letter]. Lancet 355:1886, 2000

18. Adami J, Gabel H, Lindelof B, et al: Cancer risk following organ transplantation: a nationwide cohort study in Sweden. Br J Cancer 89:1221, 2003

19. Agraharkar ML, Cinclair RD, Kuo YF, et al: Risk of malignancy with long-term immunosuppression in renal transplant recipients. Kidney Int 66:383, 2004

20. Morath C, Mueller M, Goldschmidt H, et al: Malignancy in renal transplantation. J Am Soc Nephrol 15:1582, 2004

21. Garnier JL, Lebranchu Y, Touraine JL, et al: Hodgkin's disease after transplantation. Transplant Proc 27:1785, 1995

22. Wimmer CD, Rentsch M, Crispin A, et al: The janus face of immunosuppression-de novo malignancy after renal transplantation: the experience of the Transplantation Center Munich. Kidney Int 71:1271, 2007

23. Webster AC, Wong G, Craig JC, et al: Managing cancer risk and decision making after kidney transplantation. Am J Transplant $8: 2185,2008$

24. Kasiske BL, Snyder JJ, Gilbertson DT, et al: Cancer after kidney transplantation in the United States. Am J Transplant 4:905, 2004

25. Grulich AE, van Leeuwen MT, Falster MO, et al: Incidence of cancers in people with HIV/AIDS compared with immunosuppressed transplant recipients: a meta-analysis. Lancet 370:59, 2007

26. Vajdic CM, McDonald SP, McCredie MRE, et al: Cancer incidence before and after kidney transplantation. JAMA 296: 2823, 2006

27. Kahan BD, Yakupoglu YK, Schoenberg L, et al: Low incidence of malignancy among sirolimus/cyclosporine-treated renal transplant recipients. Transplantation 80:748, 2005

28. Buhaescu I, Izzedine H, Covic A: Sirolimus challenging current perspectives. Ther Drug Monit 28:577, 2006

29. Letavernier E, Peraldi MN, Parient A, et al: Proteinuria following a switch from calcineurin inhibitors to sirolimus. Transplantation 80:1198, 2005

30. Ekberg H, Tedesco-Silva H, Demirbas A, et al: Reduced exposure to calcineurin inhibitors in renal transplantation. N Engl J Med 357:2562, 2007 